\title{
Impact of maximum borehole depths on inverted temperature histories in borehole paleoclimatology
}

\author{
H. Beltrami ${ }^{1}$, J. E. Smerdon ${ }^{2}$, G. S. Matharoo ${ }^{1}$, and N. Nickerson ${ }^{3}$ \\ ${ }^{1}$ Environmental Sciences Research Centre, St. Francis Xavier University, 1 West Street, Antigonish, \\ Nova Scotia, B2G 2W5, Canada \\ ${ }^{2}$ Lamont-Doherty Earth Observatory of Columbia University, Palisades, NY, USA \\ ${ }^{3}$ Department of Earth Sciences, Dalhousie University, Halifax, Canada
}

Received: 23 January 2011 - Published in Clim. Past Discuss.: 23 February 2011

Revised: 4 June 2011 - Accepted: 18 June 2011 - Published: 18 July 2011

\begin{abstract}
A quantitative assessment is presented for the impact of the maximum depth of a temperature-depth profile on the estimate of the climatic transient and the resultant ground surface temperature (GST) reconstruction used in borehole paleoclimatology. The depth of the profile is important because the downwelling climatic signal must be separated from the quasi-steady state thermal regime established by the energy in the Earth's interior. This component of the signal is estimated as a linear increase in temperature with depth from the lower section of a borehole temperature profile, which is assumed to be unperturbed by recent changes in climate at the surface. The validity of this assumption is dependent on both the subsurface thermophysical properties and the character of the downwelling climatic signal. Such uncertainties can significantly impact the determination of the quasi-steady state thermal regime, and consequently the magnitude of the temperature anomaly interpreted as a climatic signal. The quantitative effects and uncertainties that arise from the analysis of temperature-depth profiles of different depths are presented. Results demonstrate that widely different GST histories can be derived from a single temperature profile truncated at different depths. Borehole temperature measurements approaching $500-600 \mathrm{~m}$ depths are shown to provide the most robust GST reconstructions spanning 500 to $1000 \mathrm{yr}$ BP. It is further shown that the bias introduced by a temperature profile of depths shallower than $500-600 \mathrm{~m}$ remains even if the time span of the reconstruction target is shortened.
\end{abstract}

\section{Correspondence to: $\mathrm{H}$. Beltrami} (hugo@stfx.ca)

\section{Introduction}

The last several decades have witnessed increasing research efforts to quantify and explain the variability of the climate system during the Common Era (2000 yr BP) (e.g. Jones et al., 2009). These efforts have been motivated, in part, by observed increases in mean global temperatures during the 20 th century and projected future increases in global temperatures during the 21st century (Bindoff et al., 2007; Jansen et al., 2007; Randall et al., 2007). Placing these modern observations and projections in context is thus an important means of evaluating the magnitude, extent and impacts of the projected warming. Such context can only be achieved by characterising climatic conditions prior to the advent of the instrumental record, which has been done on myriad spatial and temporal scales using climatic proxies. The Common Era has become an important paleoclimatic interval of focus because the widespread availability and high temporal resolution of proxy records during this time period offer the potential for large-scale reconstructions on seasonal and annual timescales. Nevertheless, many uncertainties also exist in the interpretation of paleoclimatic proxies, and it is therefore important to better understand the sources, character and magnitude of these uncertainties so that paleoclimatic reconstructions of the Common Era can be properly interpreted. The purpose of this study is to evaluate a source of uncertainty in the interpretation of one type of paleoclimatic indicator, namely temperature-depth profiles measured in terrestrial boreholes.

Borehole temperature-depth profiles are used as paleoclimatic indicators by inverting the profiles to yield a temperature time series at the ground surface. These inversions

Published by Copernicus Publications on behalf of the European Geosciences Union. 
assume that long-term changes in the energy balance at the ground surface propagate conductively into the terrestrial subsurface where they are recorded as anomalies on the background signal associated with the outward flow of heat from the Earth's interior. The estimated changes in ground surface temperatures (GSTs) from borehole temperature inversions have been shown to agree well with surface air temperatures (SATs) during their period of overlap (Beltrami et al., 1992; Huang et al., 2000; Harris and Chapman, 2001; Pollack and Smerdon, 2004). This agreement, when combined with results from modelling and observational studies of air and ground temperature coupling, has supported the assumption that multidecadal to centennial changes in SAT are coupled to equivalent changes in GST and, hence, motivate the interpretation of GST reconstructions as indicators of long-term changes in SATs (see Pollack and Huang, 2000; Bodri and Cermak, 2007; González-Rouco et al., 2009, for reviews and related references).

A large collection of work has inferred GST variations during the last five centuries to a millennium (Lewis, 1992; Huang et al., 2000; Beltrami and Harris, 2001; Pollack and Huang, 2000; Harris and Chapman, 2001; Beltrami, 2002; Beltrami and Bourlon, 2004; Pollack and Smerdon, 2004; Bodri and Cermak, 2007; González-Rouco et al., 2009) and estimated GST histories as long-term (centennial) trends that are generally consistent with meteorological and other paleoclimatic records (e.g. Pollack and Smerdon, 2004; Pollack et al., 2006). Indeed, a wide range of research around the general subject of interpreting geothermal climate signals has developed over the last two decades (see Pollack and Huang, 2000; Bodri and Cermak, 2007; González-Rouco et al., 2009, for reviews and related references), including recent efforts to estimate heat storage in the terrestrial subsurface (Beltrami, 2001, 2002; Baker and Baker, 2002; Beltrami et al., 2002, 2006a; Huang, 2006) and assessments of the long-term behaviour of GCMs and the suitability of their component soil models (Lynch-Stieglitz, 1994; Sun and Zhang, 2004; Smerdon and Stieglitz, 2006; Beltrami et al., 2006b; González-Rouco et al., 2003, 2006, 2009; Stevens et al., 2007, 2008; MacDougall et al., 2008, 2010; Lawrence et al., 2008).

One advantage of GST reconstructions is that they are derived from a direct measure of temperature. In this sense, they are not a proxy for past temperatures inasmuch as they are indicative of a direct temperature response to the integrated changes in the energy balance at the Earth's continental surface. Temperature reconstructions from geothermal data are thus independent of meteorological records - a characteristic unique within the collection of paleoclimatic proxies used to reconstruct the climate of the Common Era. Similar to all paleoclimatic methods, however, the borehole method has advantages and disadvantages. One disadvantage is that borehole reconstructions suffer from reduced resolution back in time, and can only resolve multidecadal to centennial temperature changes (e.g. Clow, 1992; Harris and
Chapman, 1998). There are also a number of uncertainties associated with interpretations of borehole reconstructions that require further investigation. One such example that has received a considerable amount of attention is assessments of the relationship between GST and SAT signals at various timescales, which can be altered by surface conditions such as variations in the onset, duration and depth of snow cover, land use changes, vegetation evolution and change, and longterm increases or decreases in soil moisture. (e.g. Baker and Ruschy, 1993; Putnam and Chapman, 1996; Zhang et al., 2001; Lin et al., 2003; Stieglitz et al., 2003; Beltrami and Kellman, 2003; Bartlett et al., 2004, 2005; Pollack et al., 2005; Zhang, 2005; Bense and Kooi, 2004; Bense and Beltrami, 2007; Hu and Feng, 2005; Ferguson and Beltrami, 2006; Ferguson et al., 2006; Smerdon et al., 2003, 2004, 2006, 2009; Sushama et al., 2006, 2007; Demetrescu et al., 2007; Cey, 2009).

One uncertainty that is widely recognized in interpretations of borehole temperature profiles, but has not been quantitatively characterised in terms of the impact on derived GST reconstructions, is the degree to which these reconstructions are impacted by the maximum depth of the profile. Because the vast majority of measured temperature profiles are acquired from boreholes of opportunity, the maximum measurement depth varies considerably (beginning at depths as shallow as $100-150 \mathrm{~m}$ and extending to depths of more than $1 \mathrm{~km}$ ). The principal reason why the depth of the borehole is important stems from the fact that the downwelling climatic signal must be separated from the quasi-steady state signal associated with the upwelling of heat from the Earth's interior. This latter component of the signal is estimated as a linear increase in temperature with depth from the lower section of a borehole temperature profile, which is assumed to be unperturbed by the downwelling component of the surface signal. The validity of this assumption is dependent on both the thermophysical properties of the subsurface and the character of the downwelling climatic signal, giving rise to multiple sources of uncertainty associated with the determination of the steady-state signal. Such uncertainties can significantly impact the determination of the quasi-steady-state thermal regime, and consequently the magnitude of the temperature anomaly interpreted as a climatically induced signal.

The purpose of this study is to illustrate how the maximum depth of a temperature-depth profile impacts the estimation of the downwelling climate signal, and consequently the derived GST reconstruction. In particular, we quantitatively illustrate the effects and uncertainties that arise from the analysis of borehole temperature logs of different depths. Our results demonstrate that different GST histories can be derived from temperature profiles truncated at different depths, even when the profiles are generated from the identical surface and subsurface conditions. 


\section{Theoretical framework}

Temperatures in the first several hundred metres beneath the terrestrial surface - the depth range in which climatic signals of the past several centuries reside - are governed principally by two processes: the outward flow of heat from the planetary interior and the downward propagating temperature perturbations arising from time-varying temperatures at the land-atmosphere boundary. Changes in the outward heat flux from the planetary interior occur on time scales of millions of years; thus in the context of decadal, centennial or millennial climatic changes, the outward heat flux and its subsurface temperature signature can be considered to be in steady-state. For the regions of the subsurface relevant to GST reconstructions, this steady-state signal is approximated as a linearly increasing temperature signal with depth. If robustly identified, the steady-state temperature signal can therefore be separated from the more rapidly changing subsurface temperatures driven by climate-related fluctuations at the surface. Nevertheless, in some cases the downwelling surface signal can impact the estimate of the background thermal regime if the lower depth range of an available temperature profile the region over which the background thermal regime is estimated - is significantly perturbed by the downwelling signal. Hence, it is widely acknowledged within the borehole paleoclimatic literature that deeper boreholes are preferable, but this preference has been balanced against the practical limitation of available borehole depths.

Various studies discuss the maximum borehole depth and in some cases have explicitly considered means of inferring whether or not the lower depths of a borehole are significantly affected by downwelling surface signals. As a general rule, the Global Database of Borehole Temperatures and Climate Reconstructions applies $200 \mathrm{~m}$ as a minimum depth criterion (Pollack and Huang, 2000), and comprises the database used by many of the global borehole reconstruction analyses (e.g. Pollack et al., 1998; Huang et al., 2000; Beltrami, 2002; Harris and Chapman, 2001; Pollack and Smerdon, 2004). Chisholm and Chapman (1992) discuss the fact that borehole temperatures between the depths $100-160 \mathrm{~m}$ can be affected by past climatic perturbations and that only boreholes deeper than $500 \mathrm{~m}$ can typically avoid this problem. Harris and Chapman (2001) estimate the background thermal regime in all analysed boreholes using data below $160 \mathrm{~m}$, a depth that is argued to be "sufficient to avoid more recent climate change effects, but that retains enough data in the deeper subsurface to obtain robust estimates" of the background regime. Similarly, Majorowicz et al. (2002) perform synthetic experiments that tested inversions for different maximum borehole depths. They report depths below $150-200 \mathrm{~m}$ to be sufficient for their analyses of boreholes in Canada. It is important to note, however, that the numerical experiments on which this conclusion was based used synthetic borehole profiles generated with a surface temperature history comprising a linear increase in temperature over
150 years. Given the realistic thermophysical properties used by Majorowicz et al. (2002) to model their subsurface profiles, such a surface temperature history would never yield perturbations below about $100-150 \mathrm{~m}$. As we show in this study, temperature fluctuations that occur prior to the advent of the instrumental record can impact borehole profiles well below such depths and therefore require much deeper maximum borehole depths to adequately identify an unperturbed background steady-state signal. Such considerations make the Majorowicz et al. (2002) study difficult to interpret. Notably, Harris and Chapman (1995) and Roy et al. (2002) both propose means of estimating the depth to which surface perturbations have significantly affected temperature profiles, below which they argue that the background thermal regime can be safely estimated. These approaches, nevertheless, have not been adopted widely in the literature. Furthermore, despite these discussions in the literature, the potential impact of borehole depths on the estimated background thermal regime and the subsequent GST inversion have not been quantitatively characterised.

\subsection{Model for synthetic temperature profiles}

Our synthetic analyses employ temperature profiles generated using a one-dimensional conductive model that assumes uniform subsurface thermal diffusivity, no interior heat sources, a time varying surface boundary condition, and a lower boundary at infinity. We impose an upper boundary condition comprising a series of step changes in temperature over uniform time intervals. For these conditions, the temperature anomaly at depth $z$ and time $t$, due to a step change in surface temperature $T_{0}$, is determined by the solution of the one-dimensional heat diffusion equation (Carslaw and Jaeger, 1959):

$T(z, t)=T_{0} \operatorname{erfc}\left(\frac{z}{2 \sqrt{\kappa t}}\right)$,

where erfc is the complementary error function and $\kappa$ is the thermal diffusivity of the subsurface. Generalizing this solution for a series of $K$ step changes at the surface (Mareschal and Beltrami, 1992), the induced temperature anomalies at depth are given by:

$T_{t}(z)=T_{i}(z)+\sum_{k=1}^{K} T_{k}\left[\operatorname{erfc}\left(\frac{z}{2 \sqrt{\kappa t_{k}}}\right)-\operatorname{erfc}\left(\frac{z}{2 \sqrt{\kappa t_{k-1}}}\right)\right]$,

where $T_{i}(z)$ represents the initial temperature profile. Given a known upper boundary condition, Eq. (2) allows the subsequent subsurface perturbations to be calculated as a function of time. We thus use Eq. (2) later in our analysis to generate synthetic temperature profiles given an established surface boundary condition.

\subsection{Inversion method}

Inversions of temperature-depth profiles seek to estimate the time-varying boundary condition that has given rise to the 
measured profile at a specific moment in time (Cermak, 1971; Vasseur et al., 1983; Shen and Beck, 1991; MacAyeal et al., 1991; Wang, 1992; Mareschal and Beltrami, 1992; Bodri and Cermak, 1995; Cooper and Jones, 1998). The inverse problem requires the determination of the equilibrium surface temperature, $T_{0}$, the geothermal gradient, $\Gamma_{0}$, the bottom boundary condition and the time-varying upper boundary condition from the measured $T(z)$ data. Note that the surface heat flux is formally required in the general inversion case, but an estimate of the geothermal gradient can be used for inversions that assume uniform thermophysical properties in the subsurface, as we do here. $T_{0}$ and $\Gamma_{0}$ can be estimated from the upward continuation of a linear trend estimated from the deepest part of the temperature profile, assumed to be the depth range least affected by recent ground surface temperature changes. The data, data geometry, a priori information, model and the physics of the problem can be setup in matrix form (Mareschal and Beltrami, 1992) that will be solved here using singular value decomposition (SVD) (Lanczos, 1961; Jackson, 1972; Menke, 1989), although our results are also valid for other inversion techniques (Rath and Mottaghy, 2007; Shen and Beck, 1992; Beck et al., 1992; Wang, 1992; Hartmann and Rath, 2005; Hopcroft et al., 2007, 2009a,b). Details of the SVD method are well documented and can be found in Mareschal and Beltrami (1992); Clauser and Mareschal (1995); Beltrami and Mareschal (1995), and Beltrami et al. (1997).

\section{Results}

\subsection{Synthetic temperature anomalies}

In the following subsections, we generate an artificial borehole temperature profile, truncate it to simulate measurements down to different depths under the same climatic conditions, evaluate the corresponding temperature anomalies and invert them using the SVD method to estimate the GST history (i.e., the upper boundary condition). We then compare the results with the artificial forcing function.

We chose an upper boundary condition to act as a time varying GST function based on typical results obtained from previous analyses of geothermal data in Eastern Canada (Shen and Beck, 1992; Beltrami et al., 1992, 1997; Beltrami and Mareschal, 1992). The chosen function (Fig. 1a) consists of a static temperature period from $1000 \mathrm{yr}$ BP to $500 \mathrm{yr} \mathrm{BP}$, at which point a cooling period commences and reaches a minimum temperature of $-1.4 \mathrm{~K}$ at about $250 \mathrm{yr} \mathrm{BP}$. This cold minimum is followed by a warming period that reaches approximately $1 \mathrm{~K}$ at present day. All temperature changes are expressed here as departures from the temperature at $1000 \mathrm{yr} \mathrm{BP}$. This upper boundary condition is used to drive the forward model (Eq. 2) to generate the present-day subsurface temperature anomaly profile shown in Fig. 1b, using the canonical thermal diffusivity value of $10^{-6} \mathrm{~m}^{2} \mathrm{~s}^{-1}$ (Cermak

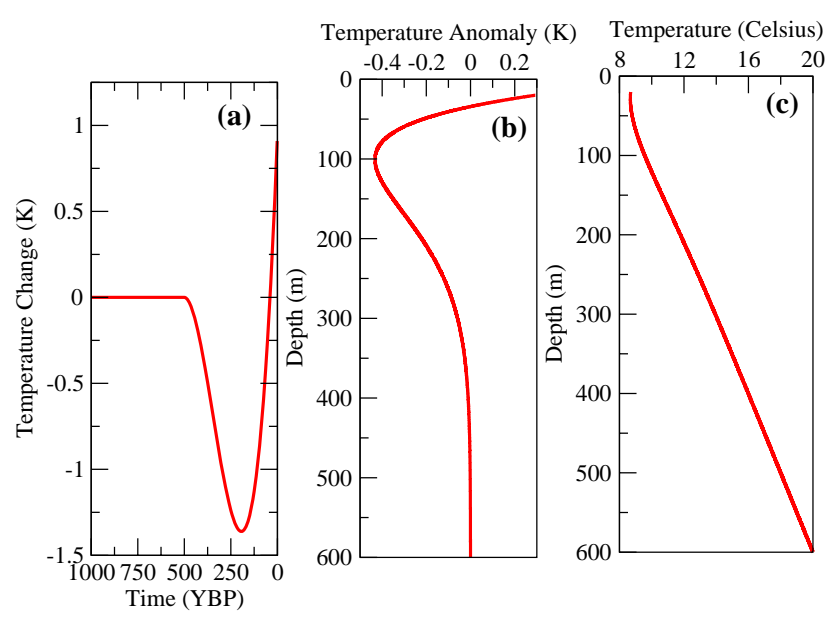

Fig. 1. (a) Synthetic ground surface temperature function used to generate the synthetic temperature-depth anomaly shown in (b). The simulated temperature log (c) was constructed by adding (b) to an equilibrium surface temperature of $8.0^{\circ} \mathrm{C}$, and a steady-state geothermal gradient of $20 \mathrm{~K} \mathrm{~km}^{-1}$.

and Rybach, 1982). To simulate field-acquired geothermal data, that is, temperature-depth profiles that include the thermal effects from the quasi-steady state geothermal regime, we add an equilibrium surface temperature and geothermal gradient to the anomaly profile generated above. The chosen values are $8^{\circ} \mathrm{C}$ and $20 \mathrm{~K} \mathrm{~km}^{-1}$, respectively, which are typical of some regions in Canada (Beltrami et al., 1992). The full synthetic temperature-depth profile is shown in Fig. 1c.

To mimic standard analyses in borehole climatology, we assume that our measured data are those of our synthetic temperature-depth profile in Fig. 1c. We generate a family of temperature profiles by truncating the full synthetic profile at varying depths. We estimate $T_{0}$ and $\Gamma_{0}$ for each sampling using a least-squares linear fit to the $100 \mathrm{~m}$ at the bottom of each of the truncated temperature profiles, as is typically done for real-world measurements (e.g. Bullard, 1939; Jaupart and Mareschal, 2011). Once the steady-state background components are estimated they are subtracted from the truncated profiles to generate the temperature anomalies associated with the estimated downwelling climatic components captured in each depth range. Figure 2 shows a set of the subsurface temperature anomalies generated from the collection of temperature profiles truncated at the indicated depths. These anomalies represent the subsurface climate signal that would be estimated if the temperature log was, in fact, measured to these depths and indicates that the magnitude and shape of the signal is impacted strongly by the depth of the borehole.

The value of the thermal diffusivity controls the vertical extent of the downwelling climatic signal and thus the depth of the borehole that is influenced by a given surface history. To illustrate the potential effect of spatially variable subsurface thermophyical properties on the temperature anomalies, 


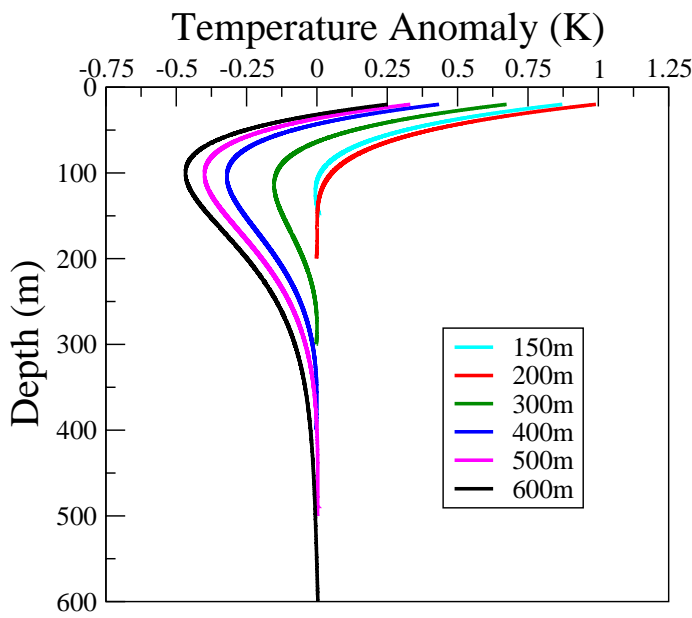

Fig. 2. Subsurface temperature anomalies estimated from the simulated temperature profile of Fig. 1c truncated at the depths indicated. The plotted temperature anomalies were derived by subtracting the equilibrium surface temperature and geothermal gradient, both of which were estimated by a least-squares linear regression on the bottom $100 \mathrm{~m}$ of each truncated profile.

we generate three sets of temperature profiles using a range of thermal diffusivity values, but identical surface temperature histories. Figure 3 shows synthetic temperature anomalies simulated as previously described, for thermal diffusivities $(\kappa)$ of $0.5,1.0$ and $1.5 \times 10^{-6} \mathrm{~m}^{2} \mathrm{~s}^{-1}$. This range of variability is excessive given that the thermal diffusivities of common crustal rocks typically vary within a range of $\pm 10 \%$ about the canonical value (e.g. Cermak and Rybach, 1982; Carslaw and Jaeger, 1959). Nevertheless, Fig. 3 serves to illustrate that different subsurface thermal properties could not realistically reconcile the depth range of the surface history penetration, given the specific history that we have adopted. Furthermore, while certain small characteristics are different, the gross impact of the maximum borehole depth on the estimated subsurface anomaly profile is clearly consistent across all three values of thermal diffusivity, as illustrated in Fig. 3 for the anomalies estimated from boreholes truncated at 200 and $600 \mathrm{~m}$ depths.

\subsection{Inversion of synthetic subsurface anomalies}

We use SVD to invert the set of subsurface temperature anomalies of Fig. 2 and derive estimates of the respective surface temperature changes. The model chosen for each individual SVD inversion (Mareschal and Beltrami, 1992) consists of a series of twenty 50-year step changes in ground surface temperature. The value of the thermal diffusivity was set at $10^{-6} \mathrm{~m}^{2} \mathrm{~s}^{-1}$ for both the generation of the synthetic data and for the inversion. The eigenvalue cutoff was set at 0.025 for each GST history inversion, keeping five principal components for all of the temperature-depth profiles included in the the reconstruction (Beltrami, 2002). Results from the
Temperature Anomaly (K)

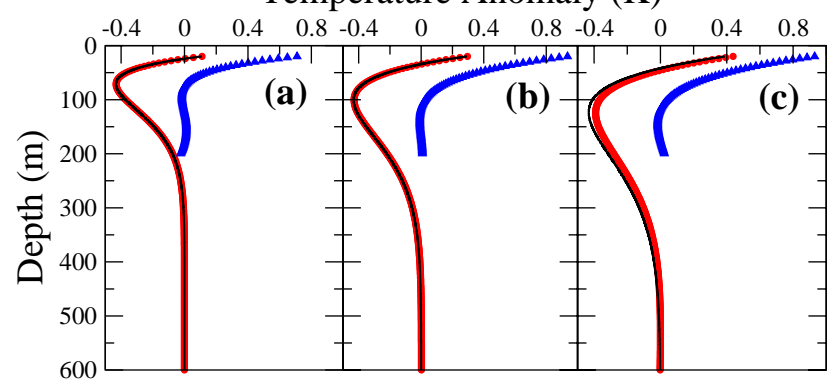

Fig. 3. Temperature anomalies (black lines) generated from the same artificial GSTH as in Fig. 1, but shown here for several values of subsurface thermal diffusivities $(\kappa)$ : (a) 0.5 , (b) 1.0 and (c) $1.5 \times 10^{-6} \mathrm{~m}^{2} \mathrm{~s}^{-1}$. Red dots correspond to the anomalies estimated from boreholes truncated at $600 \mathrm{~m}$ and blue triangles for those estimated from boreholes truncated at $200 \mathrm{~m}$.

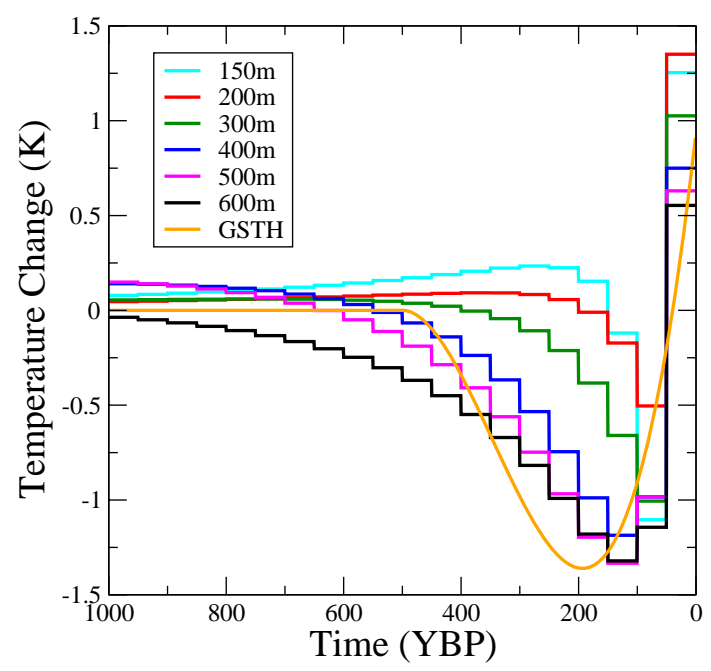

Fig. 4. Ground surface temperature histories obtained from a SVD inversion of the synthetic subsurface temperature anomalies in Fig. 2. The GST models in all of the inversions consist of a series of twenty 50-year time steps, evenly spaced over the 1000-year period. The legend indicates the maximum depth of the temperature $\log$ for each inversion. The "true" synthetic GST history is shown in orange and is the same curve shown in Fig. 1a. A thermal diffusivity of $10^{-6} \mathrm{~m}^{2} \mathrm{~s}^{-1}$ was assumed in all of the inversions.

inversion for each of the synthetic temperature anomalies and its corresponding maximum profile depth are shown in Fig. 4. As expected, none of these inversions recover the GST function in full detail because of the resolution losses associated with thermal diffusion (Mareschal and Beltrami, 1992; Clow, 1992; Beltrami and Mareschal, 1995; Harris and Chapman, 1998). The temperature anomaly obtained from the deepest borehole, however, recovers the original function most faithfully. All inversions seem to recover the recent warming, but the overall solutions differ greatly as the minimum borehole depth decreases. We also observe in Fig. 4 a temporal shift 

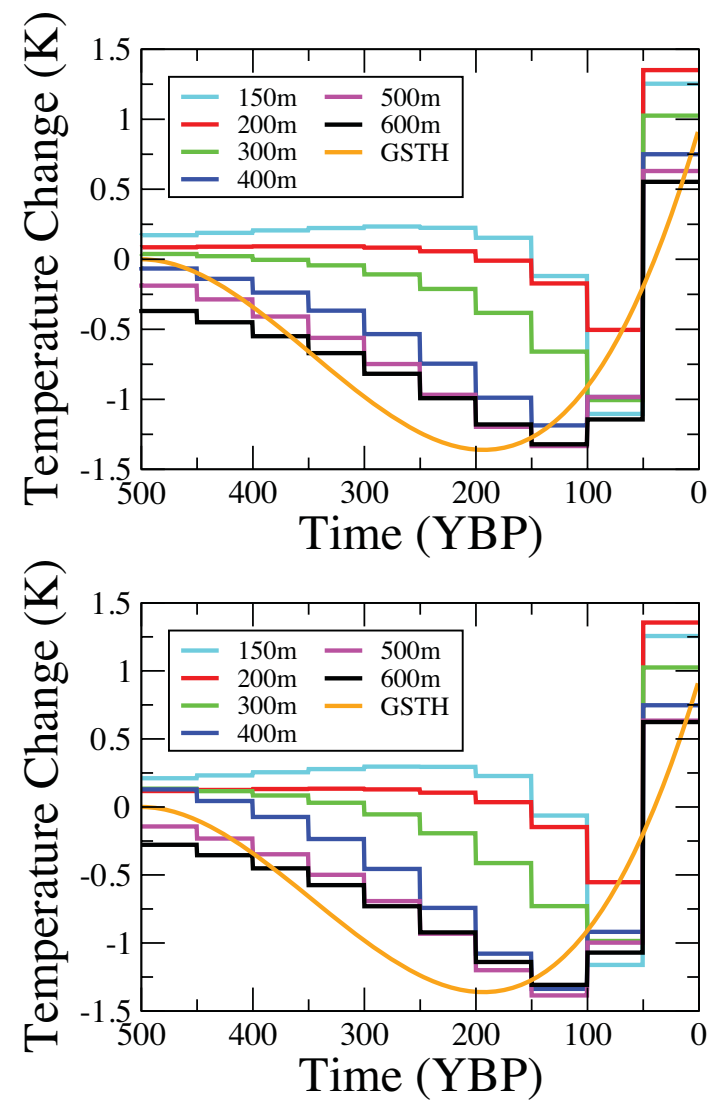

Fig. 5. (a) Ground surface temperature histories using the 1000year inversion model of Fig. 3, but only plotted back to $500 \mathrm{yr}$ BP. (b) GST histories for a 500-year inversion model consisting of ten 50-year surface temperature step changes. A thermal diffusivity of $10^{-6} \mathrm{~m}^{2} \mathrm{~s}^{-1}$ was assumed in all of the inversions.

in the minimum GST, as well as a change in its magnitude as the depth of the anomaly decreases.

As an additional test, we repeated the inversion of the family of temperature anomalies for the depths considered in Fig. 2, but only inverted for a surface temperature history that extends to $500 \mathrm{yrBP}$ (maintaining the same time step duration and eigenvalue cutoff). Figure $5 \mathrm{a}$ and $\mathrm{b}$ show the solutions for the 1000-year model of Fig. 4, but only back to $500 \mathrm{yr} \mathrm{BP}$ and the results for the inversion employing the 500-year model. The solutions are very similar and show that the choice of the temporal length of the model has little influence on the GST history.

Figure 6 shows the results for iterative estimates of the variation in the equilibrium surface temperature and geothermal gradient as functions of the maximum depth of the profile. The steady state parameters are estimated from the bottom $100 \mathrm{~m}$ of the profile, while the minimum depth of the profile is truncated iteratively by $1 \mathrm{~m}$ up to a depth of $100 \mathrm{~m}$. Although this rate of truncation would rarely be possible with real-world data, it nevertheless illustrates well the apparent variability of the steady state geothermal regime as

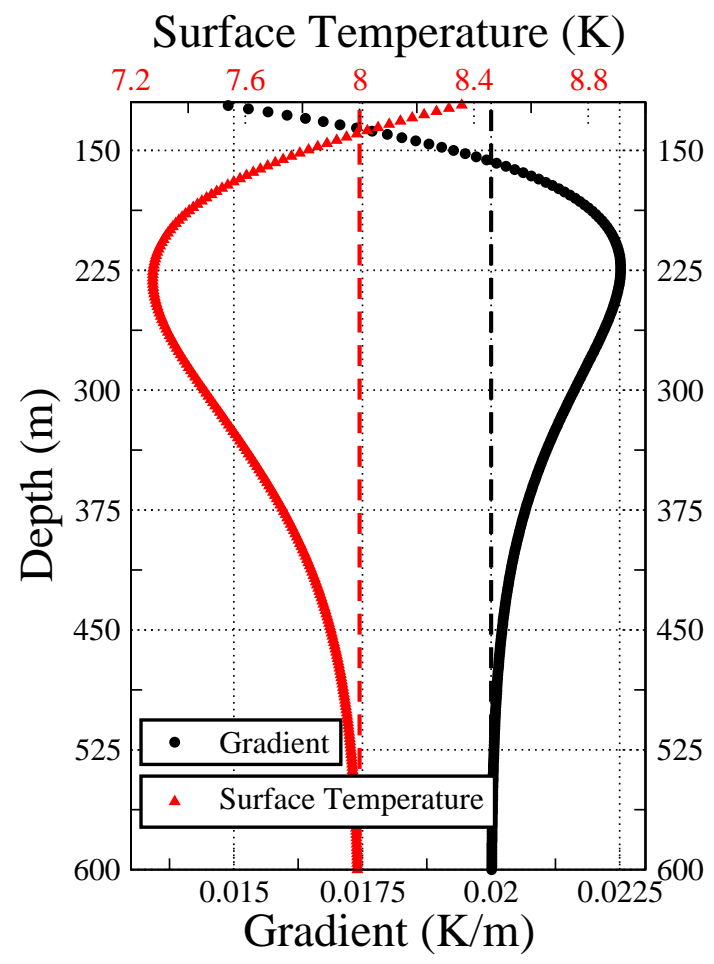

Fig. 6. Changes in the estimated equilibrium surface temperature, $T_{0}$, and geothermal gradient, $\Gamma_{0}$, as a function of borehole depth using the synthetic borehole log shown in Fig. 1c. The known and equilibrium surface temperature $\left(T_{0}\right)$ of $8.0^{\circ} \mathrm{C}$, and a steady-state geothermal gradient $\left(\Gamma_{0}\right)$ of $20 \mathrm{~K} \mathrm{~km}^{-1}$ are recovered at depths approaching 500-600 m.

the depth is reduced. In this particular case, using the chosen synthetic upper boundary condition, the correct parameters are best recovered from the deepest temperature log. Figure 6 also helps illustrate that the forcing function itself (i.e., the true climatic history) can affect the identification of the required minimum depth of a temperature-depth profile. In other words, the depth to which a borehole should be measured to avoid erroneous estimates of the background thermal regime depends on the climate history at a given location.

\subsection{Inversion of a measured temperature-depth profile}

To compare the inversion results derived in the above synthetic test with results from observational data, we chose a measured temperature-depth profile from the Canadian data base. In keeping with previous work on method verification and benchmarking for borehole paleoclimatology, we chose CA-016 (Canadian Geothermal Database number for Minchin Lake) (Neilsen and Beck, 1989; Beck et al., 1992; Shen and Beck, 1992; Beltrami et al., 1997). This borehole has been measured three times, once involving continuous measurements with a sampling rate of approximately $2 \mathrm{~cm}$ for a total of about 22000 measurements over a depth range 


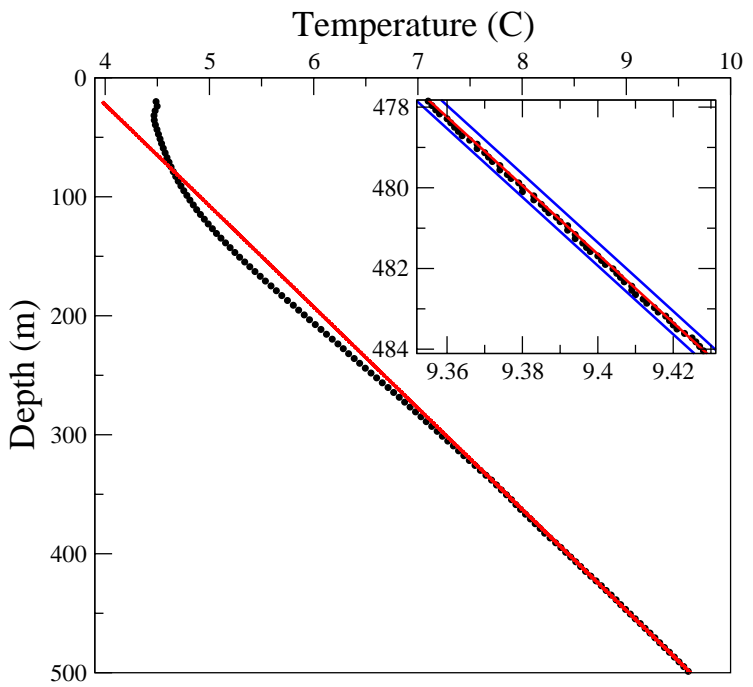

Fig. 7. Continuous temperature log for Minchin Lake (black dots). Note that only a subset of measurements have been included for clarity. The red line represents the quasi steady-state geothermal gradient estimated from a linear fit to the bottom $100 \mathrm{~m}$ of data. Inset: black dots and red lines represent the same as above, and the blue lines denote the error calculated in the slope and the intercept of the best fit line.

from 20 to $550 \mathrm{~m}$; for our experiments, we used the continuous log shown in Fig. 7. The mean value of the thermal conductivity is $3 \mathrm{~W} \mathrm{~m}^{-1} \mathrm{~K}^{-1}$ and we use $\kappa=10^{-6} \mathrm{~m}^{2} \mathrm{~s}^{-1}$ for the inversion (IHFC, 2011). Figure 8 shows the resulting temperature anomalies for approximately the same selected depths as in the synthetic test (Fig. 2). These were obtained by truncating the temperature-depth profile at the indicated depths and estimating $T_{0}$ and $\Gamma_{0}$ from a least-squares linear fit to the bottom $100 \mathrm{~m}$ of each of the truncated profiles (Bullard, 1939; Jaupart and Mareschal, 2011). Figure 9 shows the results from the inversion of the temperature anomalies for the shown depths, and illustrates behaviour similar to the results from the synthetic case. Figure 10 shows the variation of the steady-state geothermal parameters as a function of depth estimated from the same procedure used in the synthetic case above. Note that the smaller-scale variations in Fig. 10, such as those observed near the depth of $400 \mathrm{~m}$, arise due to lithological variations - not climatic changes - that are not included in the inversion procedure.

\section{Discussion and conclusions}

We have demonstrated that the maximum depth of temperature-depth profiles used for borehole paleoclimatology can have a large impact on the estimated climatic anomaly and consequently on the inverted GST history. The principal source of this effect is due to the impact of the downwelling surface temperature signal on the estimate of

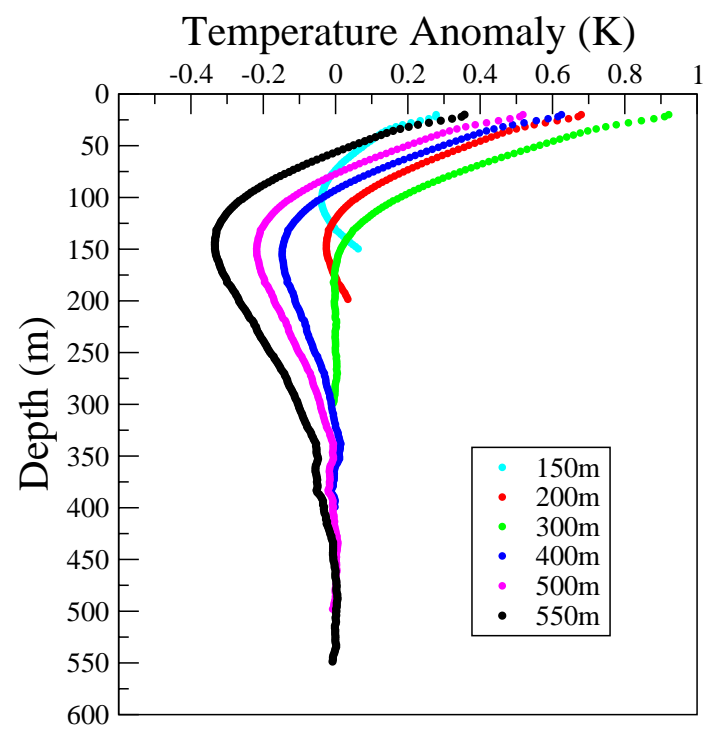

Fig. 8. Subsurface temperature anomalies estimated from the Minchin Lake temperature-depth profile after truncating the temperature log at different depths. The legend indicates the truncation depth of the profile used to calculate each of the temperature anomalies shown.

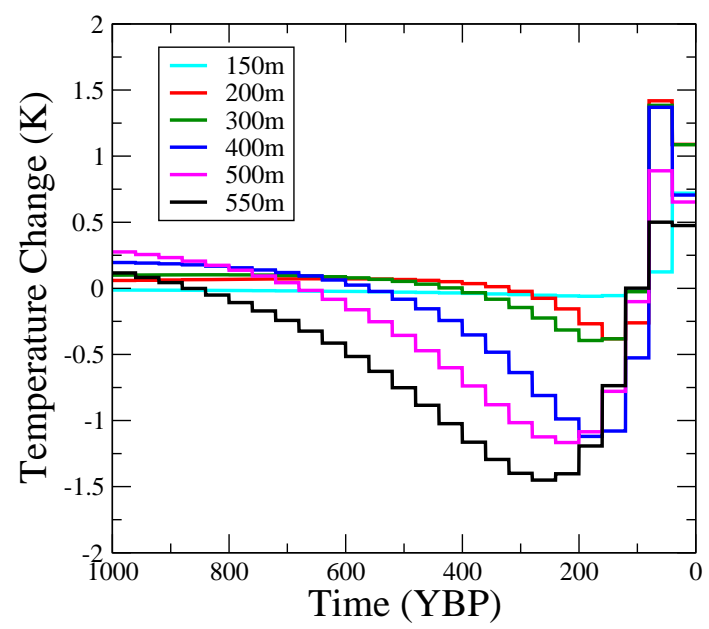

Fig. 9. Ground surface temperature histories estimated from inversions of the temperature anomalies shown in Fig. 8. Estimates of the error on the inversion parameters are not shown for clarity, but they are small because of the eigenvalue cutoff used to regularize the inversion.

the equilibrium surface temperature and geothermal gradient. These values must be estimated from a portion of the temperature-depth profile that is not significantly affected by downwelling surface perturbations in order to provide a robust estimate of the historical climatic perturbation at the surface. Our results indicate that this effect is relevant over a depth range commonly employed in borehole paleoclimatic studies. For instance, some studies have used boreholes as 


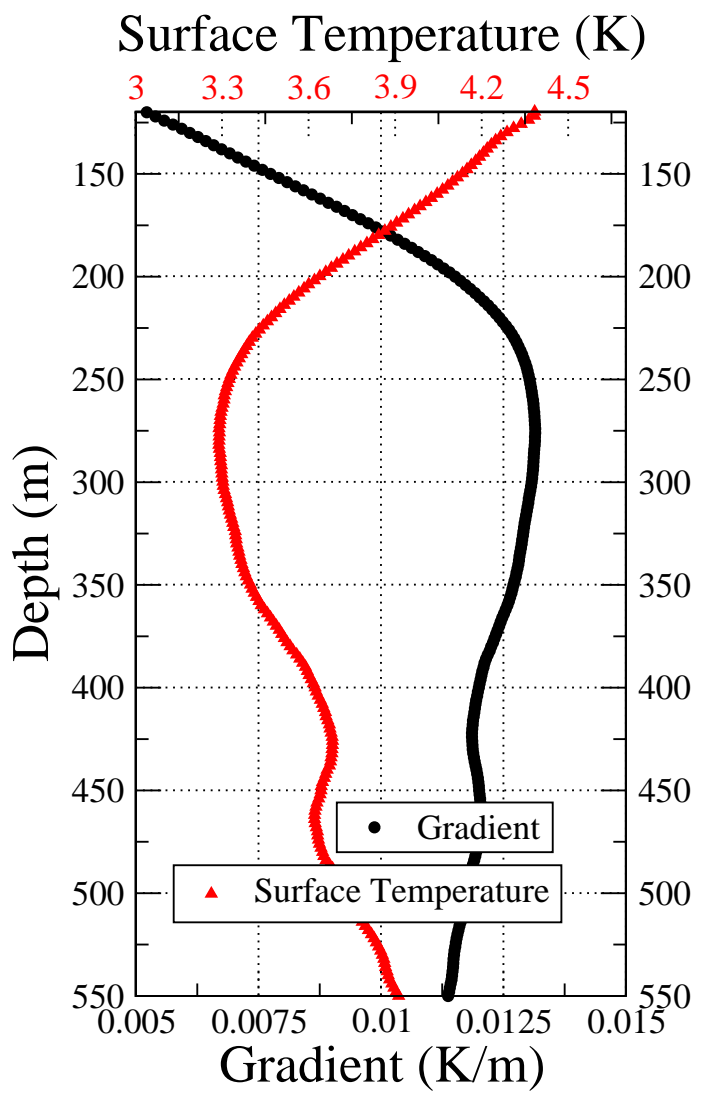

Fig. 10. Changes in the estimated equilibrium surface temperature, $T_{0}$, and geothermal gradient, $\Gamma_{0}$, as a function of depth for the temperature data measured at Minchin Lake borehole. High frequency noise due to the variability of the thermal properties is apparent. The mean value of the thermal conductivity is $3 \mathrm{~W} \mathrm{~m}^{-1} \mathrm{~K}^{-1}$ (IHFC, 2011). Note that the true equilibrium surface temperature and geothermal gradient are unknown in the observational case.

shallow as $100-150 \mathrm{~m}$ (e.g. Majorowicz et al., 1999; Majorowicz and Safanda, 2001; Majorowicz et al., 2002; Hamza et al., 2007), while the many global analyses typically set the minimum depth criterion at $200 \mathrm{~m}$ thus employing boreholes $200 \mathrm{~m}$ or deeper (Huang et al., 2000; Harris and Chapman, 2001; Beltrami, 2002; Beltrami and Bourlon, 2004; Pollack and Smerdon, 2004). Our calculations suggest that these depths are likely too shallow, but several caveats are necessary and discussed below.

The results we have quantified are dependent on both the temporal character of the upper boundary condition (i.e., the GST history) and on the thermophysical properties of the subsurface. Our analyses suggest that the range of realistic subsurface thermophyiscal properties are not likely to significantly change our conclusions. In both the synthetic and observational experiments performed in our analysis, however, the specific GST histories that gave rise to the subsurface temperature anomalies will not be applicable at all locations.
Nevertheless, in the absence of knowledge about the true climatic history of a region, which is obviously the case in most paleoclimatic studies seeking to supplement observational records, the most precautionary approach is to use the deepest possible borehole measurements. Note also that the appearance of an unperturbed lower section of the temperaturedepth profile is insufficient for impact assessments, as is clearly demonstrated from a quick inspection of the synthetic temperature $\log$ in Fig. 1c or the real $\log$ in Fig. 7. For those studies seeking to estimate GST histories between several hundred to a thousand years, our results therefore suggest that the most conservative approach would be to target measurements that extend to at least $500 \mathrm{~m}$. Furthermore, comparisons of regional GST reconstructions should, strictly speaking, only be carried out for sets of temperature-depth profiles that extend to the same depth. If subsurface thermophysical data are available, the analysis should be done for the same thermal depth incorporating in this manner the vertical variation of subsurface thermal properties.

Differences in maximum borehole depths can potentially introduce biases in the magnitude and shape of the subsurface temperature anomaly depending on the period of time considered. These biases consequently impact the estimated magnitude and temporal characteristics of recovered GST histories. Large-scale analyses that involve comparisons of results from deep and very shallow borehole temperature $\operatorname{logs}(<200 \mathrm{~m})$ (Majorowicz et al., 1999; Majorowicz and Safanda, 2001; Majorowicz et al., 2002; Hamza et al., 2007), yield results that are difficult to evaluate because of potential biases due to preferential depth ranges within regions. This potential bias does not disappear using simultaneous inversion since, as shown in Beltrami et al. (1997), the resulting GST histories are dominated by the deepest temperature log or those with larger sampling rates. Given these biases, it is important to realize that the comparison of reconstructed GST histories from temperature profiles with different maximum depths should be done with caution, as they likely do not contain climatic information for the same time interval, nor are the magnitudes of reconstructed temperatures referenced to the same initial conditions.

A final note is necessary regarding the implication of our results for hemispheric and global reconstructions derived from borehole data (e.g. Huang et al., 2000; Harris and Chapman, 2001; Beltrami, 2002; Beltrami and Bourlon, 2004; Pollack and Smerdon, 2004). These reconstructions have largely been compiled from the Global Database of Borehole Temperatures and Climate Reconstructions, which has used $200 \mathrm{~m}$ as a minimum depth criterion. As stated above, whether or not the reconstruction estimates derived from this database are subject to the potential biases that we have described is dependent on the thermophysical properties of the subsurface at each borehole location and the character of unknown prior climatic variations. If inversions from individual boreholes are affected, the gross impact observed herein is one that mutes the estimated GST warming. Similarly, for 
boreholes that measure long-term cooling, the magnitude of the estimated cooling will also be muted. The overall impact of maximum borehole depths on large-scale averages of GST reconstructions would therefore also depend on the distribution of maximum depths in boreholes that measured cooling or warming. If more boreholes measuring warming were muted, for instance, the impact would be large-scale averages that estimate less warming than actually occurred. The potential for these impacts therefore encourage more investigation. Studies that systematically evaluate the character of large-scale reconstructions derived from different minimum depth criteria are highly warranted. This will be complicated by significant losses in the number of boreholes available as the minimum depth criterion becomes deeper. For instance, Beltrami and Bourlon (2004) and González-Rouco et al. (2009) (in Figs. 1 and 6, respectively), as well as Chapman and Davis (2010) estimate that only about $10 \%$ of the boreholes in the global database extend to $600 \mathrm{~m}$. These losses in data densities will therefore need to be property accounted for. We also suggest that uncertainty analyses may be possible based on the results that we have shown. Given the known maximum depth of a borehole and the estimated thermophysical properties, synthetic tests similar to what we have shown here could be performed for a variety of temperature histories that vary, for instance, the magnitude of warming or cooling over the targeted interval. Such analyses would provide sensitivity estimates that characterise the potential for biases based on the depth of a borehole and its thermal properties. All of these approaches will ultimately help quantify the uncertainties in borehole reconstructions associated with the maximum depth of measured temperature profiles, which we have shown to be an important element of borehole paleoclimatology requiring further consideration and characterisation.

Acknowledgements. This research was supported by grants from the Canadian Foundation for Climate and Atmospheric Sciences (CFCAS), the Natural Sciences and Engineering Research Council of Canada (NSERC) and the Atlantic Innovation Fund (AIF) to HB. NN is grateful for an NSERC PGS. LDEO contribution 7484.

Edited by: J. Guiot

\section{References}

Baker, D. G. and D. L. Ruschy: The recent warming in eastern Minnesota shown by ground temperatures, Geophys. Res. Lett., 20(5), 371-374, doi:10.1029/92GL02724, 1993.

Baker, J. M. and Baker, D. G.: Long-term ground heat flux and heat storage at a mid-latitude site, Climatic Change, 54, 295303, 2002.

Bartlett, M. G., Chapman, D. S., and Harris, R. N.: Snow and the ground temperature record of climate change, J. Geophys. Res., 109, F04008, doi:10.1029/2004JF000224, 2004.
Bartlett, M. G., Chapman, D. S., and Harris, R. N.: Snow effect on North American ground temperatures, 1950-2002, J. Geophys. Res., 110, F03008, doi:10.1029/2005JF000293, 2005.

Beck, A. E., Shen, P.-Y., Beltrami, H., Mareschal, J.-C., Safanda, J., Sebagenzi, S., Vasseur, G., and Wang, K.: A Comparison of 5 different Analyses for Interpreting 5 Datasets, Global Planet. Change, 98, 101-112, 1992.

Beltrami, H.: Surface heat flux histories from geothermal data: inference from inversion, Geophys. Res. Lett., 28, 655-658, 2001.

Beltrami, H.: Climate from borehole data: energy fluxes and temperatures since 1500, Geophys. Res. Lett., 29(23), 211, doi:10.1029/2002GL015702, 2002.

Beltrami, H. and Bourlon, E.: Ground warming patterns in the northern hemisphere during the last five centuries, Earth Planet. Sc. Lett., 227, 169-177, 2004.

Beltrami, H. and Harris, R. N.: Inference of climate change from geothermal data, Global Planet. Change, 29, 148-352, 2001.

Beltrami, H. and Kellman, L.: An examination of short and long term air-ground temperature coupling at sites subjected to strong seasonal variations, Global Planet. Change, 38, 291-303, 2003.

Beltrami, H. and Mareschal, J. C.: Ground Temperature Histories for Central and Eastern Canada from Geothermal Measurements: Little Ice Age Signature, Geophys. Res. Lett., 19, 689692, 1992.

Beltrami, H. and Mareschal, J. C.: Resolution of ground temperature histories inverted from borehole temperature data, Global Planet. Change, 11, 57-70, 1995.

Beltrami, H., Jessop, A. M., and Mareschal, J. C.: Ground temperature histories in eastern and central Canada from geothermal measurements: Evidence of climate change, Global Planet. Change, 98, 167-183, 1992.

Beltrami, H., Cheng, L., and Mareschal, J. C.: Simultaneous inversion of borehole temperature data for past climate determination, Geophys. J. Int., 129, 311-318, 1997.

Beltrami, H., Smerdon, J. E., Pollack, H. N., and Huang, S.: Continental heat gain in the global climate system, Geophys. Res. Lett., 29(8), 1167, doi:10.1029/2001GL014310, 2002.

Beltrami, H., González-Rouco, J. F., and Stevens, M. B.: Subsurface temperatures during the last millennium: Model and observation, Geophys. Res. Lett., 33, L09705, doi:10.1029/2006GL026050, 2006a.

Beltrami, H., Bourlon, E., Kellman, L., and González-Rouco, J. F.: Spatial patterns of ground heat gain in the northern hemisphere, Geophys. Res. Lett., 33, L06717, doi:10.1029/2006GL025676, 2006b.

Bense, V. and Beltrami, H.: The impact of horizontal groundwater flow and localized deforestation on the development of shallow temperature anomalies, J. Geophys. Res., 112, F04015, doi:10.1029/2006JF000703, 2007.

Bense, V. and Kooi, H.: Temporal and spatial variations of shallow subsurface temperature as a record of lateral variations in groundwater flow, J. Geophys. Res., 109, B04103, doi:10.1029/2003JB002782, 2004.

Bindoff, N. L., Willebrand, J., Artale, V., Cazenave, A., Gregory, J., Gulev, S., Hanawa, K., Le Qur, C., Levitus, S., Nojiri, Y., Shum, C. K., Talley, L. D., and Unnikrishnan, A.: Observations: Oceanic Climate Change and Sea Level, in: Climate Change 2007: The Physical Science Basis, Contribution of Working Group I to the Fourth Assessment Report of 
the Intergovernmental Panel on Climate Change, edited by: Solomon, S., Qin, D., Manning, M., Chen, Z., Marquis, M., Averyt, K. B., Tignor, M., and Miller, H. L., Cambridge University Press, Cambridge, UK and New York, NY, USA, 2007.

Bodri, L. and Cermak, V.: Climate changes of the last millennium inferred from borehole temperatures: results from the Czech Republic Part I, Global Planet. Change, 11, 111-125, 1995.

Bodri, L. and Cermak, V.: Borehole climatology: a new method how to reconstruct climate, 3rd edition, Elsevier Science and Technology, The Netherlands, 2007.

Bullard, E. C.: Heat flow in South Africa, P. Roy. Soc. Lond. A., 173, 474-502, 1939.

Cermak, V.: Underground temperature and inferred climatic temperature of the past millennium, Paleogeogr. Paleocl., 10, 1-19, 1971.

Carslaw, H. S. and Jaeger, J. C.: Conduction of Heat in Solids, 2nd edition, Oxford Univ. Press, New York, 1959.

Cermak, V. and Rybach, L.: Thermal conductivity and specific heat of minerals and rocks, in Landolt-Bornstein; Zahlenwerte und Funktionen aus Naturwissenschaften und Technik, in: Physikalische Eigenschaften der Gesteine, (Hrsg.) Bd. 1, Teilbd. a, edited by: Angenheister, G., Springer-Verlag Berlin, Heidelberg, 305-343, 1982.

Cey, B. D.: On the accuracy of noble gas recharge temperatures as a paleoclimate proxy, J. Geophys. Res., 114, D04107, doi:10.1029/2008JD010438, 2009.

Chapman, D. S. and Davis, M. G.: Climate Change: Past, Present, and Future, Eos Trans. AGU, 91(37), 325-332, doi:10.1029/2010EO370001, 2010.

Chisholm, T. J. and Chapman, D. S.: Climate change inferred from analysis of borehole temperatures: an example from western Utah, J. Geophys. Res., 97, 14155-14176, 1992.

Clauser, C. and Mareschal, J. C., Ground temperature history in central Europe from borehole temperature data, Geophys. J. Int., 121, 805-817, 1995.

Clow, G. D.: The extent of temporal smearing in surface temperature histories inferred from borehole temperature measurements, Global Planet. Change, 98, 81-86, 1992.

Cooper, G. R. J. and Jones, M. Q. W.: Optimized inversion of borehole temperature data, Geophysics, 63, 331, 1998.

Demetrescu, C., Nitoiu, D., Boroneant, C., Marica, A., and Lucaschi, B.: Thermal signal propagation in soils in Romania: conductive and non-conductive processes, Clim. Past, 3, 637-645, doi:10.5194/cp-3-637-2007, 2007.

Ferguson, G. and Beltrami, H.: Transient Lateral Heat Flow due to Land-Use Changes, Earth Planet. Sc. Lett., 252, 217-222, doi:10.1016/j.epsl.2005.12.001, 2006.

Ferguson, G., Beltrami, H., and Woodbury, A.: Perturbation of ground surface temperature reconstructions by groundwater flow, Geophys. Res. Lett., 33, L13708, doi:10.1029/2006GL026634, 2006.

González-Rouco, J. F., von Storch, H., and Zorita, E.: Deep soil temperature as proxy for surface air-temperature in a coupled model simulation of the last thousand years, Geophys. Res. Lett., 30, 2116-2119, 2003.

González-Rouco, J. F., Beltrami, H., Zorita, E., and von Storch, H.: Simulation and inversion of borehole temperature profiles in simulated climates: spatial distribution and surface coupling, Geophys. Res. Lett., 33, L01703, doi:10.1029/2005GL024693,
2006.

González-Rouco, J. F., Beltrami, H., Zorita, E., and Stevens, M. B.: Borehole climatology: a discussion based on contributions from climate modeling, Clim. Past, 5, 97-127, doi:10.5194/cp-5-972009, 2009.

Hamza, V. M., Cavalcanti, A. S. B., and Benyosef, L. C. C.: Surface thermal perturbations of the recent past at low latitudes - inferences based on borehole temperature data from Eastern Brazil, Clim. Past, 3, 513-526, doi:10.5194/cp-3-513-2007, 2007.

Harris, R. N. and Chapman, D. S.: Climate change in the Colorado Plateau of eastern Utah inferred from borehole temperatures, J. Geophys. Res., 100, 6367-6381, 1995.

Harris, R. N. and Chapman, D. S.: Geothermics and climate change 1. Analysis of borehole temperatures with emphasis on resolving power, J. Geophys. Res., 103(B4), 7363-7370, 1998.

Harris, R. N. and Chapman, D. S.: Mid latitude $\left(30^{\circ}-60^{\circ} \mathrm{N}\right)$ climatic warming inferred by combining borehole temperature with surface air temperature, Geophys. Res. Lett., 28, 747-750, 2001.

Hartmann, A. and Rath, V.: Uncertainties and shortcomings of ground surface temperature histories derived from inversion of temperature logs, J. Geophys. Eng., 2, 299-311, 2005.

Hopcroft, P. O., Gallagher, K., and Pain, C. C.: Inference of past climate form borehole temperature data using Bayesian Reversible Jump Markov chain Monte Carlo, Geophys. J. Int., 171, 14301439, doi:10.1111/j.1365-246X.2007.03596.x, 2007.

Hopcroft, P. O., Gallagher, K., and Pain, C. C.: A Bayesian partition modelling approach to resolve spatial variability in climate records from borehole temperature inversion, Geophys. J. Int., 178, 651-666, doi:10.1111/j.1365-246X.2009.04192.x, 2009a.

Hopcroft, P. O., Gallagher, K., Pain, C. C., and Fang, F.: Threedimensional simulation and inversion of borehole temperatures for reconstructing past climate in complex settings, J. Geophys. Res., 114, F02019, doi:10.1029/2008JF001165, 2009 b.

$\mathrm{Hu}$, Q. and Feng, S.: How have soil temperatures been affected by the surface temperature and precipitation in the Eurasian continent?, Geophys. Res. Lett., 32, L14711, doi:10.1029/2005GL023469, 2005.

Huang, S.: 1851-2004 annual heat budget of the continental landmasses, Geophys. Res. Lett., 33, L04707, doi:10.1029/2005GL025300, 2006.

Huang, S., Pollack, H. N., and Shen, P. Y.: Temperature trends over the last five centuries reconstructed from borehole temperatures, Nature, 403, 756-758, 2000.

IHFC - International Heat Flow Commission contributors to the Borehole Data and Climate Reconstruction database: NOAA Paleoclimatology database, data downloaded on 22 January, 2011.

Jackson, D. D.: Interpretation of inaccurate, insufficient, and inconsistent data, Geophys. J. R. Astron. So., 28, 97-110, 1972.

Jansen, E., Overpeck, J., Briffa, K. R., Duplessy, J.-C., Joos, F., Masson-Delmotte, V., Olago, D., Otto-Bliesner, B., Peltier, W. R., Rahmstorf, S., Ramesh, R., Raynaud, D., Rind, D., Solomina, O., Villalba, R., and Zhang, D.: Palaeoclimate, in: Climate Change 2007: The Physical Science Basis, Contribution of Working Group I to the Fourth Assessment Report of the Intergovernmental Panel on Climate Change, edited by: Solomon, S., Qin, D., Manning, M., Chen, Z., Marquis, M., Averyt, K. B., Tignor, M., and Miller, H. L., Cambridge University Press, Cambridge, UK and New York, NY, USA, 2007. 
Jaupart, C. and Mareschal, J. C.: Heat generation and transport in the Earth, Cambridge University Press, 1st edition, Cambridge, UK, 464 pp., 2011.

Jones, P. D., Briffa, K. R., Osborn, T. J., Lough, J. M., van Ommen, T. D., Vinther, B. M., Luterbacher, J., Wahl, E. R., Zwiers, F. W., Mann, M. E., Schmidt, G. A., Ammann, C. M., Buckley, B. M., Cobb, K. M., Esper, J., Goosse, H., Graham, N., Jansen, E., Kiefer, T., Kull, C., Kuttel, M., Mosley-Thompson, E., Overpeck, J. T., Riedwyl, N., Schulz, M., Tudhope, A. W., Villalba, R., Wanner, H., Wolff, E., and Xoplaki, E.: High-resolution paleoclimatology of the last millennium: a review of current status and future prospects, Holocene, 19, 3-49, 2009.

Lanczos, C.: Linear Differential Operators, D. Van Nostrand, New York, 564 pp., 1961.

Lawrence, D. M., Slater, A. G., Romanovsky, V. E., and Nicolsky, D. J.: Sensitivity of a model projection of near-surface permafrost degradation to soil column depth and representation of soil organic matter, J. Geophys. Res., 113, F02011, doi:10.1029/2007JF000883, 2008.

Lewis, T.: Climatic change inferred from underground temperatures, Global Planet. Change, 98, 78-282, 1992.

Lin, X., Smerdon, J. E., England, A. W., and Pollack, H. N.: A model study of the effects of climatic precipitation changes on ground temperatures, J. Geophys. Res., 108, D74230, doi:10.1029/2002JD002878, 2003.

Lynch-Stieglitz, M.: The development and validation of a simple snow model for GISS GCM, J. Climate, 7, 1842-1822, 1994.

MacAyeal, D., Firestone, J., and Waddington, E.: Paleothermometry by control methods, J. Glaciol., 37, 326-338, 1991.

MacDougall, A. H., Gonzalez-Rouco, J. F., Stevens, M. B., and Beltrami, H.: Quantification of subsurface heat storage in a GCM simulation, Geophys. Res. Lett., 35, L13702, doi:10.1029/2008GL034639, 2008.

MacDougall, A. H., Beltrami, H., González-Rouco, J. F., Stevens, M. B., and Bourlon, E.: Comparison of observed and general circulation model derived continental surface heat flux in the Northern Hemisphere, J. Geophys. Res., 115, D12109, doi:10.1029/2009JD013170, 2010.

Majorowicz, J. and Safanda, J.: Composite surface temperature history from simultaneous inversion of borehole temperatures in western Canadian plains, Global Planet. Change, 29, 231-239, doi:10.1016/S0921-8181(01)00092-3, 2001.

Majorowicz, J., Safanda, J., Harris, R. N., and Skinner, W. R.: Large ground surface temperature changes of the last three centuries inferred from borehole temperatures in the Southern Canadian Prairies, Saskatchewan, Global Planet. Change, 20, 227-241, 1999.

Majorowicz, J., Safanda, J., and Skinner, W.: East to west retardation in the onset of the recent warming across Canada inferred from inversions of temperature logs, J. Geophys. Res., 107(B10), 2227, doi:10.1029/2001JB000519, 2002.

Mareschal, J. C. and Beltrami, H.: Evidence for recent warming from perturbed geothermal gradients: examples from eastern Canada, Clim. Dynam., 6, 135-143, 1992.

Menke, W.: Geophysical Data Analysis: Discrete Inverse Theory, International Geophysical Series, 4, Academic Press, San Diego, 289 pp., 1989.
Nielsen, S. B. and Beck, A. E.: Heat Flow Density Values and Paleoclimate Determined From Stochastic Inversion of Four Temperature-Depth Profiles from the Superior Province of the Canadian Shield, Tectonophysics, 164, 345-359, 1989.

Pollack, H. N. and Huang, S.: Climate reconstructions from subsurface temperatures, Annu. Rev. Earth Planet. Sc., 28, 339-365, 2000.

Pollack, H. N. and Smerdon, J. E.: Borehole climate reconstructions: Spatial structure and hemispheric averages, J. Geophys Res., 109, D11106, doi:10.1029/2003JD004163, 2004.

Pollack, H. N., Huang, S., and Shen, P.-Y.: Climate change record in subsurface temperatures: a global perspective, Science, 282, 279-281, 1998.

Pollack, H. N., Smerdon, J. E., and van Keken, P. E.: Variable seasonal coupling between air and ground temperatures: A simple representation in terms of subsurface thermal diffusivity, Geophys. Res. Lett., 32, L15405, doi:10.1029/2005GL023869, 2005.

Pollack, H. N., Huang, S., and Smerdon, J. E.: Five centuries of climate change in Australia: The view from underground, J. Quaternary Sci., 21, 701-706, 2006.

Putnam, S. N. and Chapman, D. S.: A geothermal climate change observatory: first year results from Emigrant Pass in northwest Utah, J. Geophys. Res., 101, 21877-21890, 1996.

Randall, D. A., Wood, R. A., Bony, S., Colman, R., Fichefet, T., Fyfe, J., Kattsov, V., Pitman, A., Shukla, J., Srinivasan, J., Stouffer, R. J., Sumi, A., and Taylor, K. E.: Cilmate Models and Their Evaluation, in: Climate Change 2007: The Physical Science Basis. Contribution of Working Group I to the Fourth Assessment Report of the Intergovernmental Panel on Climate Change, edited by: Solomon, S., Qin, D., Manning, M., Chen, Z., Marquis, M., Averyt, K. B., Tignor, M., and Miller, H.bL., Cambridge University Press, Cambridge, UK and New York, NY, USA, 2007.

Rath, V. and Mottaghy, D.: Smooth inversion for ground surface temperature histories: estimating the optimum regularization parameter by generalized cross-validation, Geoph. J. Int., 171, 1440, 2007.

Roy, S., Harris, R. N., Rao, R. U. M., and Chapman, D. S.: Climate change in India inferred from geothermal observations, J. Geophys. Res., 107(B7), 2138, doi:10.1029/2001JB000536, 2002.

Shen, P. Y. and Beck, A. E.: Least Squares Inversion of Borehole Temperature Measurements in Functional Space, J. Geophys. Res., 96(B12), 19965-19979, doi:10.1029/91JB01883, 1991.

Shen, P.-Y. and Beck, A. E.: Paleoclimate change and heat flow density inferred from temperature data in the Superior Province of the Canadian shield, Global Planet. Change, 6, 143-165, 1992

Smerdon, J. E. and Stigelitz, M.: Simulation of heat transport in the Earth's shallow subsurface: Lower-boundary sensitivities, Geophys. Res. Lett., 33, L14402, doi:10.1029/2006GL026816, 2006.

Smerdon, J. E., Pollack, H. N., Enz, J. W., and Lewis, M. J.: Conduction-dominated heat transport of the annual temperature signal in soil, J. Geophys. Res., 108, 2431, doi:10.1029/2002JB002351, 2003.

Smerdon, J. E., Pollack, H. N., Cermak, V., Enz, J. W., Kresl, M., Safanda, J., and Wehmiller, J. F.: Air-ground temperature coupling and subsurface propagation of annual temperature signals, J. Geophys. Res., 109, D21107, doi:10.1029/2004JD005056, 2004. 
Smerdon, J. E., Pollack, H. N., Cermak, V., Enz, J. W., Kresl, M., Safanda, J., and Wehmiller, J. F.: Daily, seasonal, and annual relationships between air and subsurface temperatures, J. Geophys. Res., 111, D07101, doi:10.1029/2004JD005578, 2006.

Smerdon, J. E., Beltrami, H., Creelman, C., and Stevens, M. B.: Characterizing land-surface processes: A quantitative analysis using air-ground thermal orbits, J. Geophys. Res., 14, D15102, doi:10.1029/2009JD011768, 2009.

Stevens, M. B., Smerdon, J. E., González-Rouco, J. F., Stieglitz, M., and Beltrami, H.: Effects of bottom boundary placement on subsurface heat storage: Implications for climate model simulations, Geophys. Res. Lett., 34, L02702, doi:10.1029/2006GL028546, 2007.

Stevens, M. B., González-Rouco, J. F., and Beltrami, H.: North American climate of the last millennium: Underground temperatures and model comparison, J. Geophys. Res., 113, F01008, doi:10.1029/2006JF000705, 2008.

Stieglitz, M., Dery, S. J., Romanovsky, V. E., and Osterkamp, T. E.: The role of snow cover in the warming of arctic permafrost, Geophys. Res. Lett., 30, 1721, doi:10.1029/2003GL017337, 2003.

Sun, S. and Zhang, X.: Effect if the lower boundary position of the Fourier Equation on the soil energy balance, Adv. Atmos. Sci., 21, 868-878, 2004.
Sushama, L., Laprise, R., and Allard, M.: Modeled current and future soil thermal regime for northeast Canada, J. Geophys. Res., 111, D18111, doi:10.1029/2005JD007027, 2006.

Sushama, L., Laprise, R., Caya, D., Verseghy, D., and Allard, M.: An RCM projection of soil thermal and moisture regimes for North American permafrost zones, Geophys. Res. Lett., 34, L20711, doi:10.1029/2007GL031385, 2007.

Vasseur, G., Bernard, P., Van de Meulebrouck, J., Kast, Y., and Jolivet, J.: Holocene paleotemperatures deduced from geothermal measurements, Palaeogeogr. Palaeocl., 43, 237-259, 1983.

Wang, K.: Estimation of ground surface temperatures from borehole temperature data, J. Geophys. Res., 97, 2095-2106, doi:10.1029/91JB02716, 1992.

Zhang, T.: Influence of the seasonal snow cover on the ground thermal regime: An overview, Rev. Geophys., 43, RG4002, doi:10.1029/2004RG000157, 2005.

Zhang, T., Barry, R. G., Gilichinsky, D., Bykhovets, S. S., Sorokovikov, V. A., and Ye, J.: An Amplied signal of climatic change in soil temperatures during the last century at Irkutsk, Russia, Climatic Change, 49, 41-76, 2001. 